\title{
Smart Energy Metering Based on Arduino, GSM, and Raspberry pi3 as Server
}

\author{
Doaa.S.Al-sehail ${ }^{1}$, Osama Y.K Al-Atbee. ${ }^{2}$, Ali Marhoon ${ }^{3}$ \\ \{doaa.alsehail28@gmail.com ${ }^{1}$, usama.khader@uobasrah.edu.iq ${ }^{2}$, alifm60@gmail.com ${ }^{3}$ \} \\ ${ }^{1,2,3}$ Electrical Engineering Department, University of Basrah, Basrah, Iraq
}

\begin{abstract}
This paper proposed and implement a microcontroller-based smart meter that utilizes the GSM as wireless communication with the utility server. The scheme aims to build a low-cost smart power meter that improves the electric grid and prevents electricity loss, making life more comfortable for the consumer and utility. Raspberry Pi3 server equipped with programmed systems in highly efficient and reliable languages (PHP and Python) and secure databases (MySQL) to set up an automatic metering and billing system. The proposed system provides exchange information between the consumer and the utility, where the consumer can access his data through a web page. Issuing a monthly bill and sending it to the consumer by e-mail and SMS as well as disconnecting the power source in case the consumer fails to pay his bill.
\end{abstract}

Keywords: Smart Meter, Arduino Mega 2560 Micro-Controller, GSM SIM900A, Raspberry pi3, RTC

\section{Introduction}

Electricity has become one of the vital technology in human daily life. It is an important part of factories and homes. The world development leading to more electricity demand and consumption. With such development, calculating the power consumptions by the energy supplier's companies and producing bills using the old-style reading of the traditional meters became ineffective. There are many defects, including the complete dependence on the meter readers, as well as human errors that occur that cannot be avoided, and the time required to accomplish whole area data reading and billing. Also, there is a great chance of theft and the consumer not getting an update about the amount of energy consumed at a regular interval [1]. So the demand has increased effectively for meters that collect readings electronically, but this method has become ineffective and expensive because it requires a visit to collect the readings by a specialized employee by the company. This means a lot of time and many employees, and sometimes the consumer is not present at his house. To improve the way of collecting the meter reading, the smart meter plays an important role in eliminating the problems that were previously raised. Smart Energy Meters (SEM) are measurement devices used by utilities to deliver billing information to all customers and operating their electric systems. This is the main reason behind companies targeting SEMs, as reading and remote control help reduce workforce costs. It has become an important national strategy related to the standard of living and individual safety, as SEM can contact the individual and let him know how his money was spent on electricity. SEM is designed and implemented on a large scale and is stable in various scenarios and methods to achieve optimal cost efficiency on the electrical system [2]. Some researchers used wireless networks to establish a connection between meters and control centers to obtain the best strategy [2]. The main feature that distinguishes smart meters from other meters is their ability of two- 
way communication between the consumer and the utility [3]. There are many communication technologies currently used for smart metering systems, but (CDMA, GSM, WIMAX, ZigBee, and WLAN) are among the most widespread communication technologies in the world, the above methods except GSM are very expensive to implement and operate requires complex infrastructure setup, short remote operation and still requires field intervention from human operators or is prone to error and reliability problem due to noise in a transmission line or weather condition [4]. GSM is the best technology currently used because it is widely available, very reliable, and inexpensive compared to means of communication. Other SEM automation based on GSM [4] uses a current sensor to measure the value of current consumed by the load and PIC to convert the value that gets from the sensor to a digital unit. Automatic power metering using ZigBee and GPRS [5]. A pic181e4620 microcontroller was used with the cc2430 as a communication function and supports the Zigbee protocol, as it can transmit data up to 10 meters indoors and about 200 meters outdoors. This data is collected by Zigbee and sent via GPRS using $\operatorname{sim} 300$ to the service provider, but one of the drawbacks of this work is that the bill is not presented to the consumer. IoT Energy monitoring system [6] It is suggested that data be sent every 20 seconds to the Raspberry Pi 3 server via Wi-Fi type esp8288, where the user can access the information used about the energy consumed over the internet to that server as well as use josn (Java Object Script Notation) and also the data is processed through Server to calculate the amount of energy consumed during the day. Zigbee power meter [7]. An SEM is designed to calculate the voltage, current, and power factor and to send the obtained data to the home compliant gateway via the Zigbee protocol, but one of the disadvantages of this method is that it cannot be used in long distances. Prepaid energy meter based on GSM and RFID [8] a design of master card reader and energy meter that informs the consumer about his energy consumption via GSM. Smart meter with deployment network [9] presented system consists of energy meter installed in each home and raspberry pi as a server. The consumed power will be compared with the available balance for the same home at the server. The drawback of this system is the use of a power line carrier (PLC) which is expensive and not always available. This paper presents a wireless smart energy meter topology to overcome the drawbacks and improves the traditional energy meters system. An Arduino microcontroller with the GSM as a communication tool with the Raspberry Pi server and other peripherals are utilized to propose a smart energy metering system. the developed system can provide a detailed measurement of power usage and energy consumption patterns. Thus, the consumer can Understand their electricity usage patterns so they can adapt their behavior to reduce their energy profile.

\section{Proposed system}

The main function of the SEM is its ability to communicate the meter reading to the resource via the communication network. For a fast and efficient means of data collection, it is preferable to use a GSM network in the proposed system for communication purposes between consumers and the utility service. The main reason for choosing GSM is due to the large network coverage, low cost, and negligible maintenance, sending data to a web server through it becomes a useful and easy-to-use tool. The Arduino-based smart metering system consisting of a smart power meter and Raspbian Linux version available for Raspberry Pi3 Model B provides the full functionalities needed for servers [10]. The data sent by the smart meter are stored on the MYSQL database within the Raspberry server which includes multiple tables. The flowchart and overall block diagram for this project are presented in Fig. 1 and Fig. 2 respectively. 


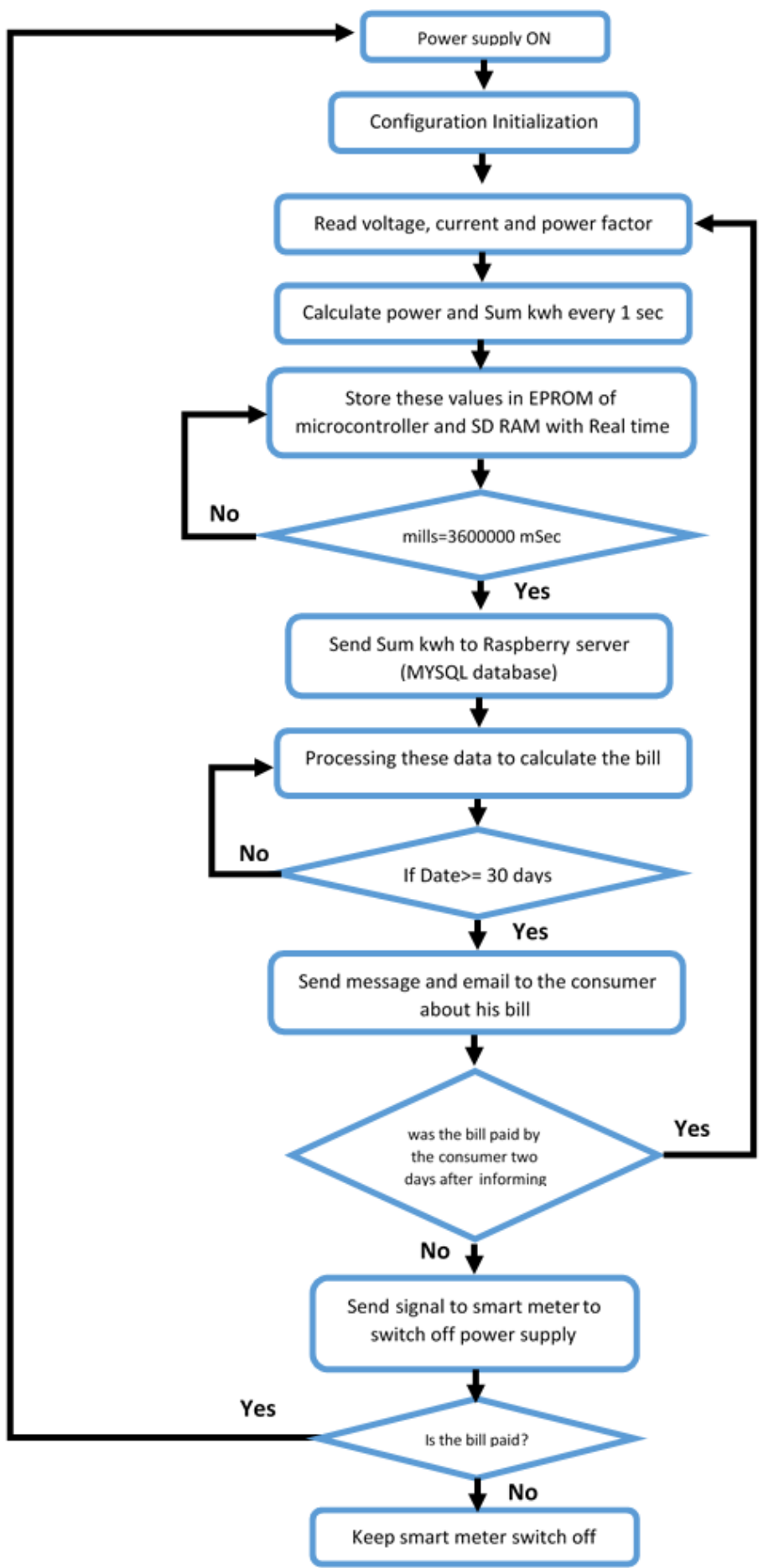

Fig. 1. The flowchart of the proposed system. 


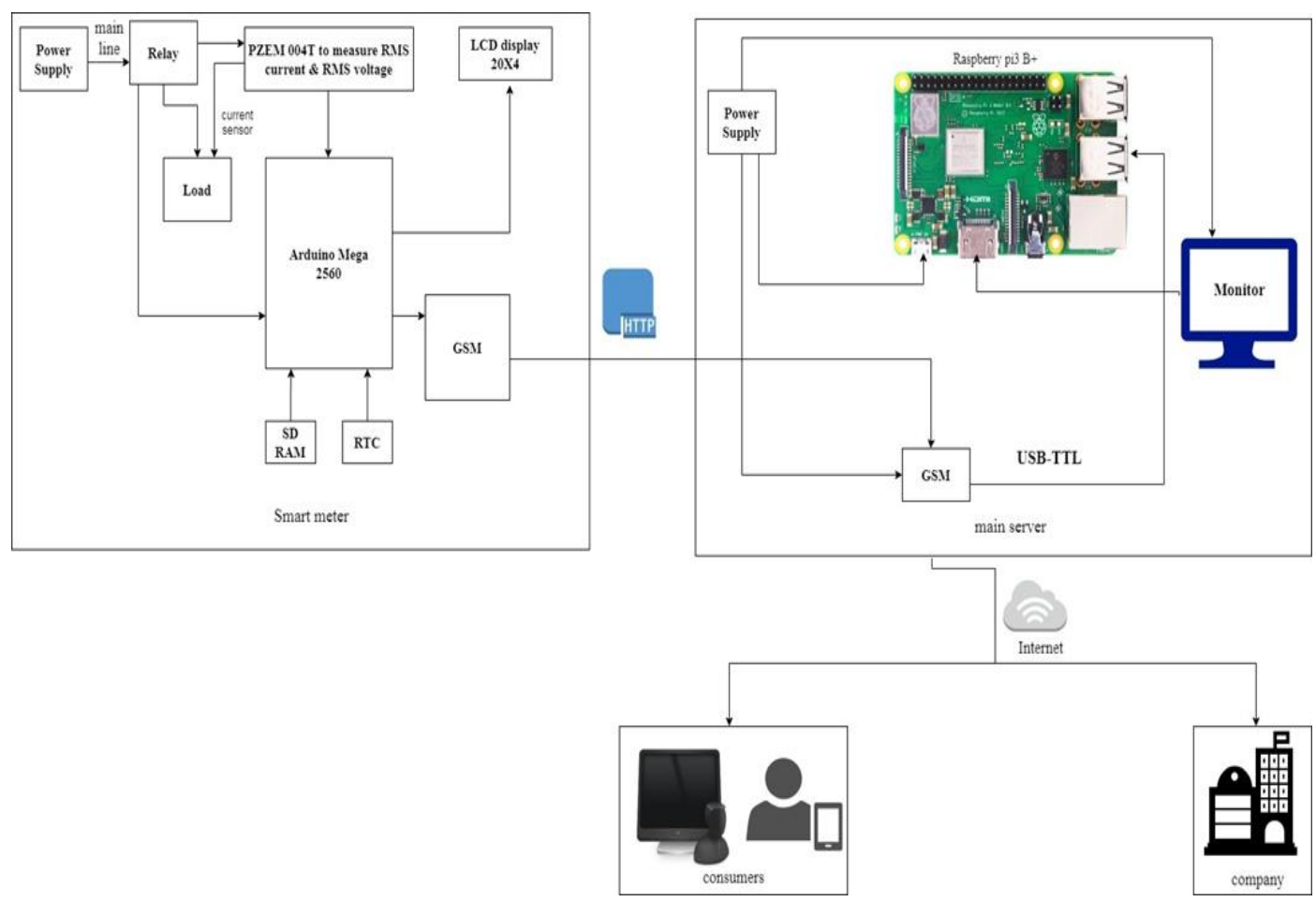

Fig. 2. The block diagram of the proposed system.

\section{Function of the proposed energy meter}

The designed meter measures RMS values for current and voltage. The measurement of RMS of the discrete signal is as follows [12]:

$$
\begin{aligned}
& \mathrm{V}_{\mathrm{RMS}}=\sqrt{\frac{1}{\mathrm{~N}} \sum_{\mathrm{N}} \mathrm{V}^{2}(\mathrm{n})} \\
& \mathrm{I}_{\mathrm{RMS}}=\sqrt{\frac{1}{\mathrm{~N}} \sum_{\mathrm{N}} \mathrm{i}^{2}(\mathrm{n})}
\end{aligned}
$$

Where, and are discrete values of voltage and current. $\mathrm{N}$ is that the number of samples during a single period of the discrete signal. The real power of the discrete-time signal is measured as follows:

$\mathrm{P}=V_{R M S} . \times I_{R M S} \times p . f$ 


\section{Implementation}

\section{A. Software Implementation}

The project was simulated in proteus 8.0. First, it needs to add a library in proteus software because the software does not support Arduino boards by default. The hex. A file of code is uploaded in Arduino boards in Proteus. The simulation of the smart Energy meter consists of the following parts:

- Voltage measurement circuit.

- Current measurement circuit.

- Relay to connect or disconnect the load.

After uploading the Arduino code, the results can be shown on the LCD as shown in Fig. 3.

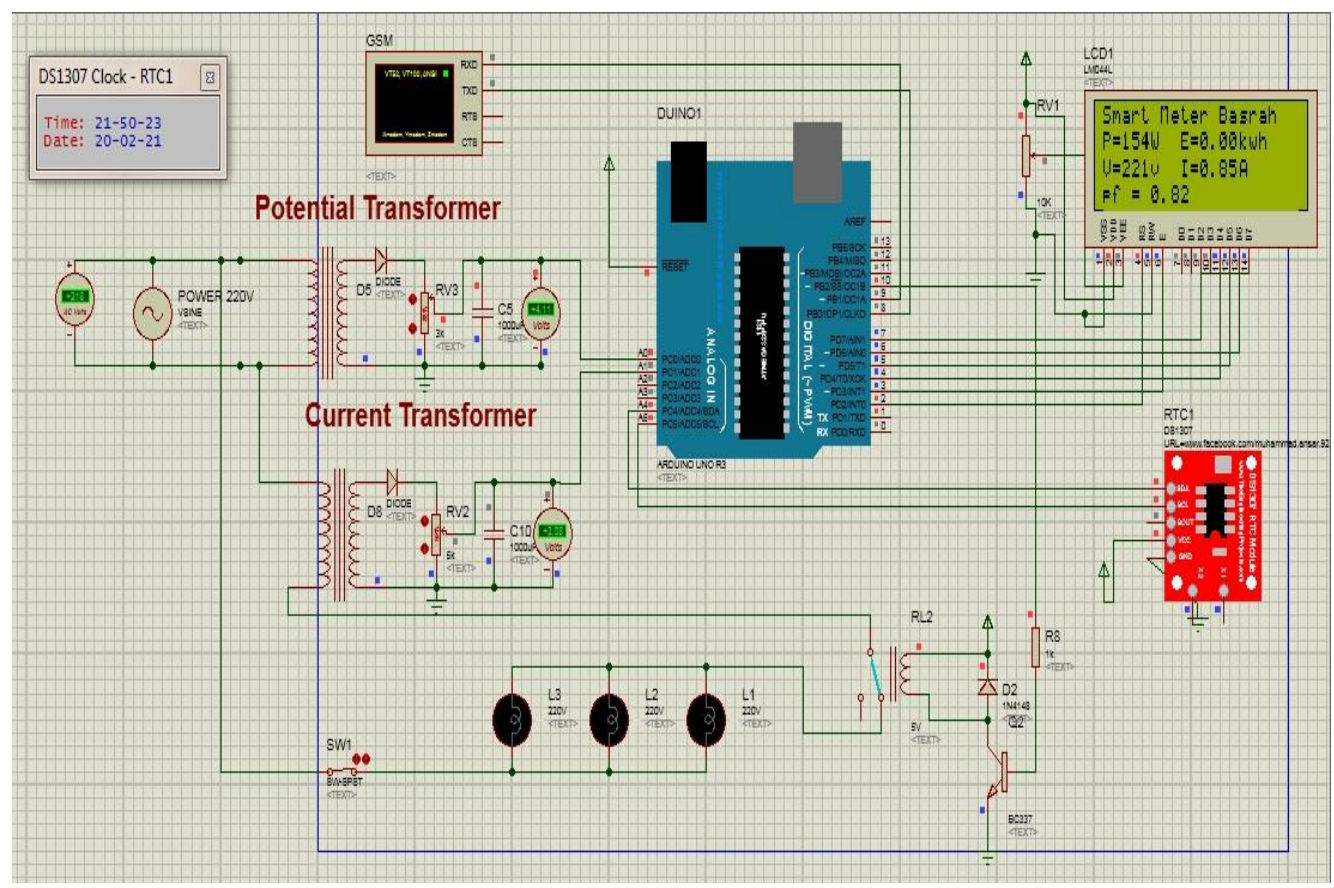

Fig.3. the simulation of the proposed system.

\section{B. Hardware Implementation}

The main components that have been used in the project are:

- $\quad$ Arduino Mega 2560

Arduino Mega 2560 is an ATMEGA 2560 based microcontroller board. It contains a total of 54 pins. Of the $54 \mathrm{I} / \mathrm{O}$ pins, 16 are analog input/output data pins and 4 are UART serial communication pins. The advantage of Arduino Mega over other microcontrollers is its higher 
graphic memory and bigger size of RAM that makes it a fast processing controller. The microcontroller needs a DC power supply of $5 \mathrm{~V}, 1$ A rating [13].

- $\quad$ Pzem 004T sensor

The module as shown in Fig. 4 is used to measure the AC voltage, current, active power, frequency, power factor, and active power, and this module is read through the TTL interface. The measuring current range of this module (10A-100A) and the voltage range (80V-380V).

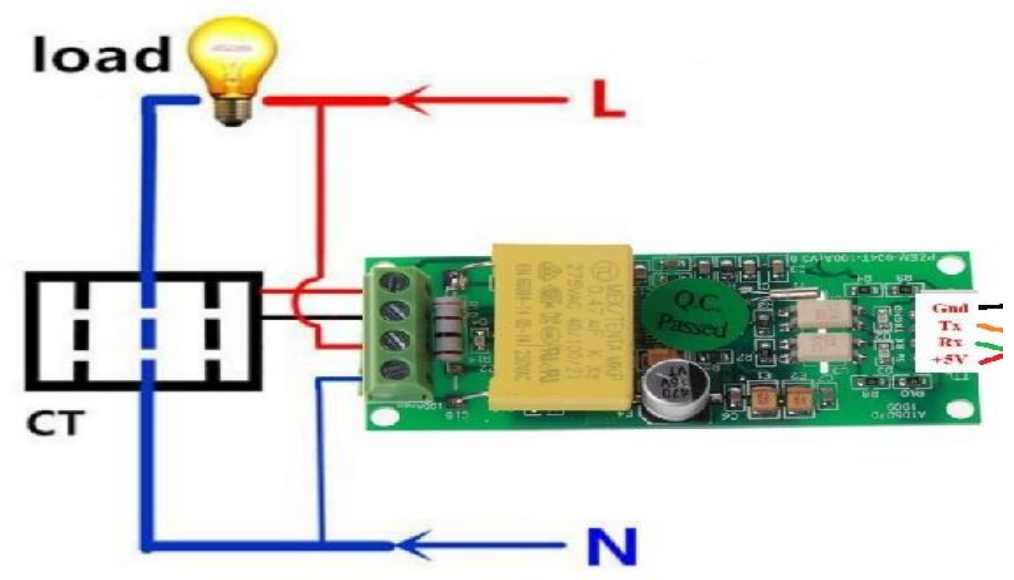

Fig. 4. PZEM 004T.

\section{- GSM Module SIM900A}

SIM 900A is a dual-band GSM / GPRS (900/1800 MHz) module. It communicates with controllers by using AT commands. As it can control the meter by sending a signal through GSM that is connected to Raspberry Pi server to the GSM located in the Smart Meter to control it and send notifications by the utility and displaying them on LCD or sending them to the consumer's mobile.

\section{- Liquid Crystal Display (LCD)}

This component is responsible for displaying consumption data in kilowatts as well as displaying tariffs and notifications sent by the approval authority and measuring power quality.

\section{- SD Card}

The Micro SD card unit is used to store the values so that the meter readings are not lost in the event of a malfunction or a problem in sending data to the server.

- Relay 
In the proposed design, a relay was included to handle remote requests by utilities, to control the connection between the main and the load. The model identified in this design is a singlechain $5 \mathrm{~V}-10 \mathrm{~A}$ power unit.

\section{- Real-Time Clocking (RTC)}

Real-Time Clock Module DS3231 used in this project is a low cost and high fidelity unit as it saves hours and minutes of Information in seconds, dates, days, months, and years. Date month which ends in less than 31 days, are automatically adjusted, including a leap year.

\section{- Raspberry pi3 B+}

It is a small, powerful, and inexpensive computer board that works the same way as a standard computer and requires a keyboard to enter commands, a display unit, and a power source. Raspberry pi 3 is used as a server because is a small single-board computer. It is ideal for use as a basic Linux desktop, media center computer, development machine, or any number of projects. It is preferable due to its low power consumption and respectable processing capabilities [10]. Databases were installed in high-level languages, MySQL, and the system was programmed in reliable languages such as PHP, and Python to control and process all data sent to this server and sending information from the server to the consumer such as invoices and other notifications about the meter status or in the event of maintenance on the electrical grid.

\section{Prototype Design}

As mentioned earlier, the Arduino Mega 2560 was used as a micro-controller with GSM to provide communication between the consumer, the smart meter, and the server, as the GSM communicates with the network and sends the data and in the event of an error such as nonpayment of the bill, a message appears on the LCD in the meter and the mobile.

Fig. 5 shows the output of SEM of the proposed system. It sends SMS to the user monthly with the number of consumed units and how much money a consumer will have to pay for the utility.

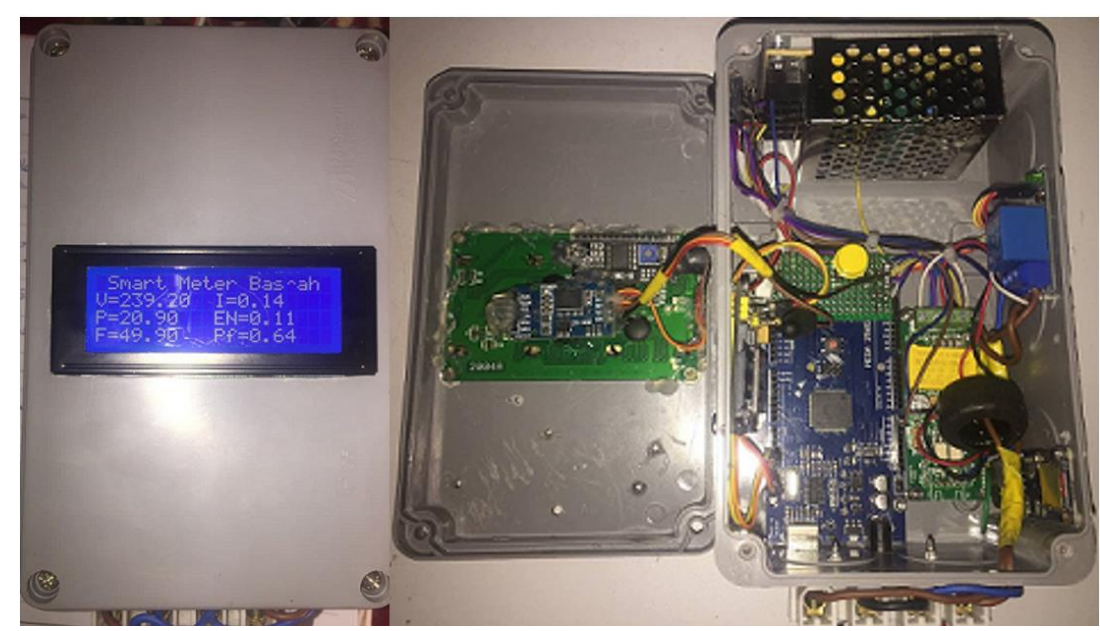

Fig. 5. Smart meter implementation. 
Fig. 6 shows the all components implemented in the proposed system. An integrated system has been designed in high-level programming languages such as (PHP, Python) to calculate the bill and send it via e-mail and SMS to the customer's mobile at the beginning of each month as shown in Fig. 7. If the bill is not paid, the electricity is disconnected from the meter through the server, and the electricity is also returned to the meter remotely. This system can also issue reports for each customer and know the status of the device, is it active or inactive. Fig. 8 shows the login page of the system that is programmed to manage the received data and processed it to control the smart meter.



Fig. 6. The implementation of the proposed system.

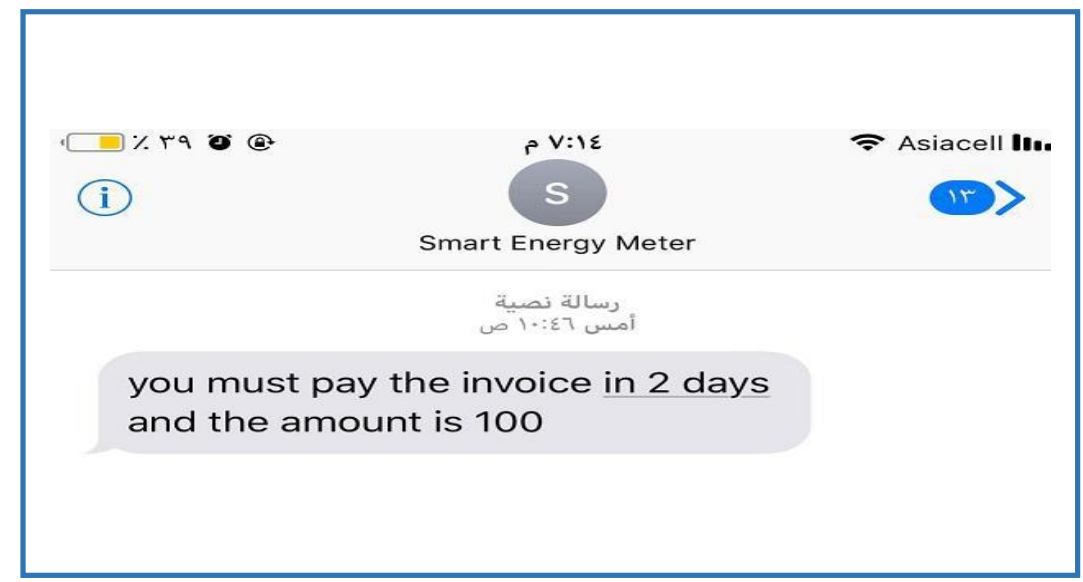

Fig. 7. Text message (SMS) sent to the consumer with the value of the monthly bill. 


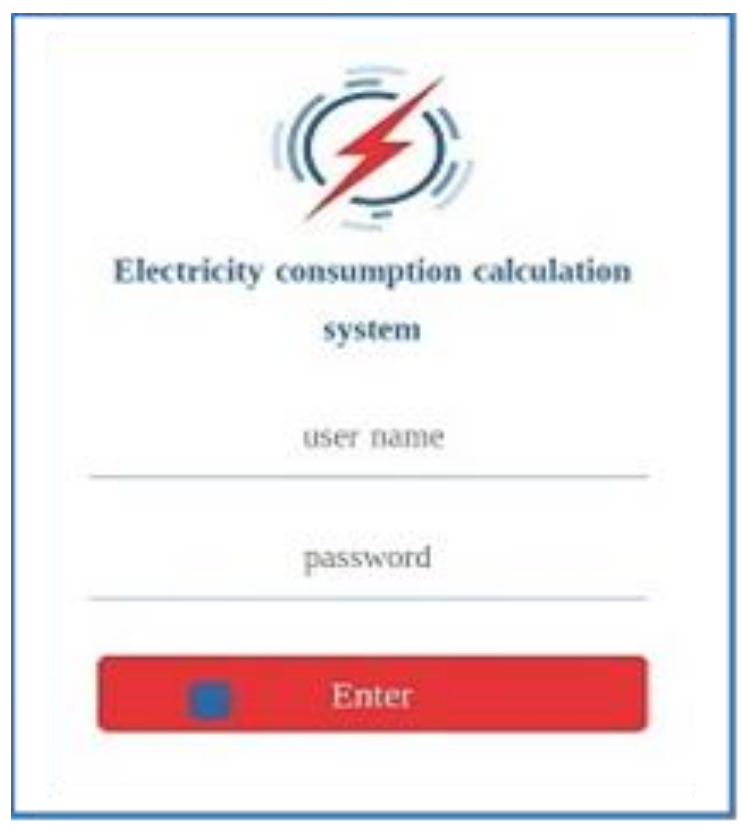

Fig.8. Login page of the system.

Fig. 9 shows the management of the smart meter webpage, the webpage has software built in PHP and PYTHON languages, the function of each icon in Fig.9 is:

- Users: the users can be added to the system to manage the system, control Meters, and adding new meters if there are new consumers.

- Customer: Adding a new customer to the system in the event of submitting an additional request, and includes recording the entire customer's data such as his name, address, phone number, e-mail, and the unique identifier of the meter. All details can also be modified in the event of a change in the added information.

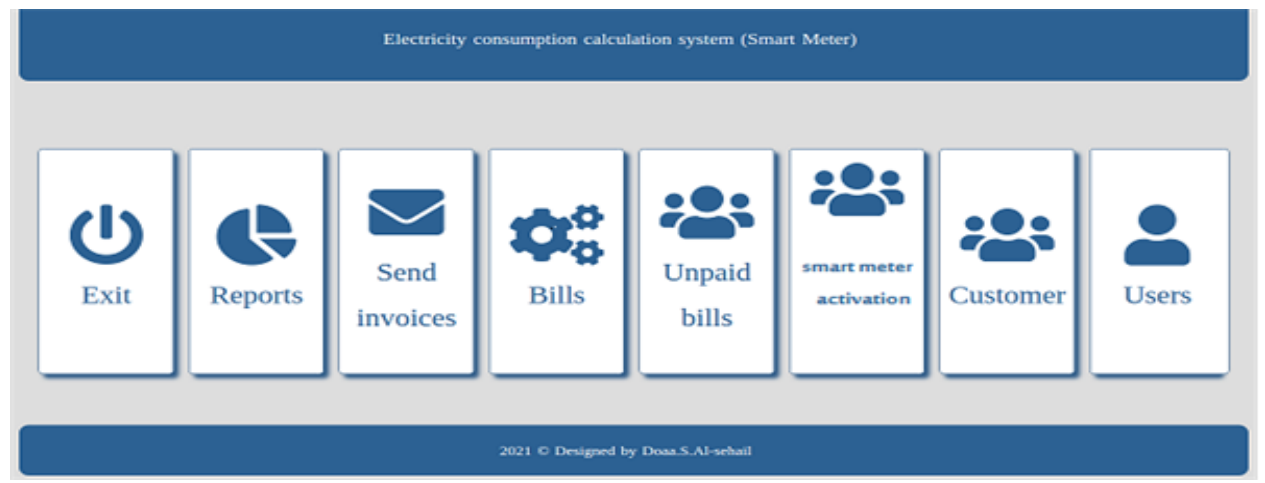

Fig. 9. Smart meter page management. 
- Smart meter activation: Revitalize the meter if it was cut off upon non-payment of the bill and the period allowed for the consumer to pay has been exceeded.

- Unpaid bills: Report of unpaid bills after exceeding the time allowed for payment.

- Bills: Issuing invoices to the consumer at the beginning of each month where the system has been programmed to issue an invoice if the server date refers to the first day of the month or when the consumer requests the bill.

- Reports: Includes all consumer reports, invoices (daily and monthly), and counter status (active or not).

Fig. 10 shows the amount of kilowatt-hour was received by the My-SQL server for two consumers that were previously added to the energy consumption system through the consumer's page within the designed system, the date and time of the consumption.



Fig. 10. The data was received from the smart meter for two consumers.

Table 1 shows a watt reading comparison of the smart meter between the simulation and the experimental setup for different load sets.

Table 1. Smart-Meter Reading.

\begin{tabular}{ccc}
\hline $\begin{array}{c}\text { Load } \\
\text { steps }\end{array}$ & $\begin{array}{c}\text { Power } \\
\text { measurements } \\
\text { (Watt) simulation }\end{array}$ & $\begin{array}{c}\text { Power measurements } \\
\text { (watt) Experimental }\end{array}$ \\
\hline 1 & 21 & 21.3 \\
2 & 263 & 262.13 \\
3 & 444 & 444.5 \\
4 & 695 & 693.4 \\
\hline
\end{tabular}




\section{Conclusion}

This paper presents a smaller, cheaper, faster scale, and wireless smart energy meter instead of the outdated energy meters. It is also relatively economical and direct to use, and at the same time provides high reliability. With the recent wireless meter system, it is possible to plan to read the values and monitor the meter readings continuously, and disconnected the power supply by the control center every time the user fails to pay the required bill on time without the need for human intervention. This feature is well managed by connected the consumer smart meter to a central control unit wirelessly. Moreover, it helps in avoiding the wrong readings that sometimes occur because of the local electricity meter readers' mistakes. Leading to save time, effort, and reduces the cost of maintenance. The designed meter provides many features that help the consumer knowing the amount of energy consumed, the bill, and the actual time for consumption. the consumer can access his account at any time he wants through his phone or Web page. All in all, the system simulation, and the smart energy meter implementation worked effectively and proves that they can replace the traditional electricity meters.

\section{References}

[1] A. S. Metering, S. Visalatchi and K. K. Sandeep, "Smart energy metering and power theft control using arduino \& GSM," 2017 2nd International Conference for Convergence in Technology (I2CT), Mumbai, 2017, pp. 858-961, doi: 10.1109/I2CT.2017.8226251.

[2] M. Burunkaya and T. Pars, "A smart meter design and implementation using ZigBee based Wireless Sensor Network in Smart Grid," 2017 4th International Conference on Electrical and Electronic Engineering (ICEEE), Ankara, 2017, pp. 158-162, doi: 10.1109/ICEEE2.2017.7935812.

[3] Danielly B. Avancini, Joel J.P.C. Rodrigues, Simion G.B. Martins, Ricardo A.L. Rabelo , Jalal Al-Muhtadi d , and Petar Solic " Energy meters evolution in smart grids: A review" Journal of Cleaner Production 217 (2019) 702e715

[4] H. G. R. Tan, C. H. Lee and V. H. Mok, "Automatic power meter reading system using GSM network," 2007 International Power Engineering Conference (IPEC 2007), Singapore, 2007, pp. 465-469.

[5] L. Quan-Xi and L.Gang "Design of remote automatic meter reading system based on ZigBee and GPRS"2010 ACADEMY PUBLISHER.

[6] K. Chooruang and K. Meekul, "Design of an IoT Energy Monitoring System," 2018 16th International Conference on ICT and Knowledge Engineering (ICT\&KE), Bangkok, 2018, pp. 1-4, doi: 10.1109/ICTKE.2018.8612412.

[7] D. Balsamo, G. Gallo, D. Brunelli and L. Benini, "Non-intrusive Zigbee power meter for load monitoring in smart buildings," 2015 IEEE Sensors Applications Symposium (SAS), Zadar, Croatia, 2015, pp. 1-6, doi: 10.1109/SAS.2015.7133611.

[8] E. I. Abbas, M. E. Safi and M. A. Jaber, "Design and Implementation Prepaid Energy Meter Supported by RFID and GSM Technologies," 2018 International Conference on Advanced Science and Engineering (ICOASE), 2018, pp. 216-220, doi: 10.1109/ICOASE.2018.8548870.

[9] N. T. Surajudeen-Bakinde, S. O. Ayodele, N. T. Surajudeen-Bakinde, T. David Oloruntoba, A. O. Otuoze and N. Faruk, "Development of an Internet based prepaid energy meter," 2017 IEEE AFRICON, 2017, pp. 1370-1373, doi: 10.1109/AFRCON.2017.8095681.

[10] M. Istifanos, I.Tekahun " performance evaluation of Raspberry pi3 B and web server" faculty of computing, bleking institute of technology, SE-371 79 Karlskrona Sweden,2020

[11] K. Ashna and S. N. George, "GSM based automatic energy meter reading system with instant billing," 2013 International Mutli-Conference on Automation, Computing, Communication, Control and Compressed Sensing (iMac4s), Kottayam, India, 2013, pp. 65-72, doi: 10.1109/iMac4s.2013.6526385. 
[12] "IEEE Standard Definitions for the Measurement of Electric Power Quantities Under Sinusoidal, Nonsinusoidal, Balanced, or Unbalanced Conditions," in IEEE Std 1459-2010 (Revision of IEEE Std 1459-2000), vol., no., pp.1-50,19March2010,doi: 10.1109/IEEESTD.2010.5439063.

[13] M.Tahir,S.Muneeb , M.S.Jan and M.Hassan "Smart Energy Meter with Advanced Features and Billing System" 2019 4th International Electrical Engineering Conference(IEEC2019). 